\title{
The Impact of Using Interactive Interior Design on Enhancing the Performance of Clothing Shop
}

\author{
Ahmad Mahmoud Obeidat ${ }^{1}$,Prof. Dr. Hussein Kamel Al-Nabawi ${ }^{2}$ Prof. Dr. Ola Ali Hashem ${ }^{3}$ \\ Ass. Prof Hany Mohammed El-Said ${ }^{4}$ \\ 1) Doctoral candidate / Interior Design and Furniture Department/ Faculty of Applied Arts/ Helwan University. \\ 2) Professor of Touristic Spaces in Interior Design and Furniture Department/ Faculty of Applied Arts/ Helwan University. \\ 3) Professor of Touristic Spaces in Interior Design and Furniture Department/ Faculty of Applied Arts/ Helwan University. \\ 4) Assistant Professor of Industrial Design Department/ Faculty of Applied Arts/ Helwan University.
}

\section{KEY WORDS:}

Interior design, interactive design, interactive interior design, shops, clothing stores, performance improvement.

\begin{abstract}
:
The interior designer is facing many challenges in the design process, to make the interior fit to the environmental and cultural conditions, and thanks to modern technology, which led to successive architectural transformations in response to the many developments in ICT, many new concepts have emerged in the field of interior design, that seek to meet human needs and future requirements. One of these concepts is interactive interior design, which necessitated the interior designer to reconsider the common design methods in order to integrate with the era of digital design. Whereas the interactive design has given shape, space and function a new meaning, it is possible to have an interaction between spaces and humans, taking into account the respect of the internal and external environment.

The research reviews the impact of using interactive design on space handling in clothing stores. By employing an interactive design in the interior spaces, to meet the needs and requirements of users and make the most of the available spaces and achieve luxury.

Whereas the use of interactive design in the determinants of the internal space of clothing stores work to solve the prevailing problems in the accumulation of spaces in the display and congestion of corridors customers and do not direct them the best direction to achieve the highest sales.
\end{abstract}

Follow the Methodological, descriptive and analytical research of models of shop that sell clothes to identify the most important design problems that exist.

The most important results were:

1. The use of interactive techniques as a guide and advertising inside the shops of clothing has facilitated the process of selecting clothes inspection and purchase without the need for spaces to change clothes.

2. The use of interactive technologies led to the organization of the sale and display of customers and the lack of congestion in the places of assembly. 


\section{INTRODUCTION:}

Interior design is a process of interaction between man, space, time and culture, where the world has recently witnessed many developments in the field of technology used in the field of interior design, that meet human needs and future requirements, through information technology associated with computers and applications in various areas of life, as a result of this Massive development in technology Many concepts have emerged in design, including interactive interior design, which is where the interaction between the user of the place and the design is achieved through the use of digital technologies inside it. The interactive space is an environment that interacts with the users within it that responds to their activity and interacts with them through a variety of forms such as Visual, auditory, Kinetic, and Haptic. As reflected in the service performance of shops, because of its impact on changing the shape of internal spaces and achieve the function and the process of interaction between the user and the space positively. Whereas many functions of interior design elements were not easily implemented, they changed the traditional concepts of interior design. This is evident in the shops of clothing and fashion, because of the nature of the products offered in terms of type and quantity as well as the density of visitors to these stores.

This development is based primarily on the required function. The determinants of the internal space are no longer merely inanimate objects used by humans, but they are able to sense the user, identify him, interact with him and adapt to his desires. In a way that reflects positively on ways to make the most of the spaces while achieving the highest satisfaction rates for customers.

\section{RESEARCH PROBLEM:}

The scarcity of interactive design solutions in the interior design of clothing stores, those that make the most of the available spaces. Especially with the increasing competitiveness and the tendency of many brands to increase the number of alternatives offered, which often conflict with the available spaces as well as the number of customers, and the ability to meet their requirements as well as achieve luxury for them. Such inconsistency may negatively affect the satisfaction of the visitors, and consequently on the targeted commercial traffic of those brands.

\section{RESEARCH OBJECTIVE:}

Problem The research aims to shed light on the role of the interior designer in the treatment and development of interior spaces in clothing stores, including work To achieve the requirements and needs of customers within them interactively improves the user experience, and to develop guidelines for how to provide the optimal solution in the processing and formation of internal space for those stores.

\section{AIMS AND OBJECTIVES:}

The research aims to shed light on the role of the interior designer in the treatment and development of interior spaces in clothing stores, including work To achieve the requirements and needs of users within them interactively improves the user experience, and to develop guidelines for how to provide the optimal solution in the processing and formation of internal space for those stores.

\section{RESEARCH HYPOTHESES:}

The research assumes that taking advantage of the positive impact of interactive design in clothing stores, help to optimize the way to make the most of the available spaces, and connect users to the brand by achieving pleasure and luxury during the shopping process.

\section{RESEARCH IMPORTANCE:}

The importance of research in monitoring the positive aspects of interactive design in the development of spaces in clothing stores, and how to use them in the development of future perceptions that are environmentally friendly and meet the needs of the user and improve his experience.

\section{RESEARCH METHODOLOGY:}

The methodological, descriptive and analytical research is followed by studying the concept of interactive interior design, as well as examples of interactive design techniques that already used to the formation of interior spaces for shops by addressing the determinants of the interior space.

\section{DESIGN SHOPS:}

The interest in interior design of the shops at the moment is very important, as the brands were most interested in the volume of sales and profit only. However, with the competition among them there is a focus on attracting a larger segment of customers, so it is neces- 
sary to pay attention to other aspects to provide a more enjoyable experience during the process of shopping. Granular in them. With the development of technology, especially in terms of interactive technologies, things have become more complex. Which necessitated attention to other aspects to attract customers, the most important ways to improve the experience of target customers, especially with regard to the ways of distribution of goods and display within the shop. With the application of Interactive Design technology in interior design, there will be interactive between the beginning of design plans and the users, in order to create a pleasant experience for the customer when entering the shop, So the Interactive Design makes spaces more people-oriented. In order to create a pleasant experience for the customer when entering the shop, and enjoy and indulge in the shopping experience and not just the experience of entering through the door to the store, this atmosphere can be created by paying attention to the details of the interior design of the shop. There are many basic factors that may affect how well the store design attracts customers and improves their brand experience. The most important of these factors are:

\section{Area:}

The area of shops varies depending on the type of activity targeted, as well as depending on the volume of the brand, as the shop must be sufficiently large to achieve the elements of a good supply of the product in a way that affects the purchase decision. Large brands tend to attract the largest segment of customers through the magnitude and diversity of the exhibits, which requires large areas Figure (1), which may not be available at times, or increase the cost of the product or crowded exhibits in the shop does not allow the formation of experience Good shopping especially in busy shopping seasons. The large spaces allow for the formation of interior spaces more flexible and commensurate with the nature of the products offered.

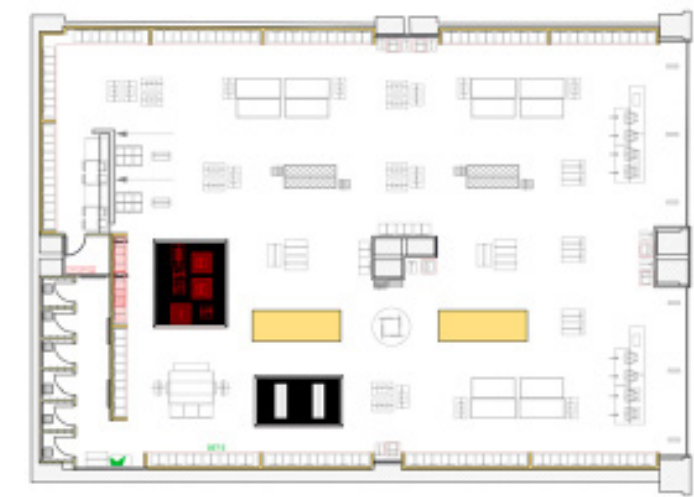

Figure (1) shows a horizontal hometown of one of the international clothing stores (Mango) with a large breadth to achieve the elements of the display

\section{Lighting:}

This is an important element in achieving good product presentation, and influences the success of the shop interior design, and the degree of clarity of colors and design elements used. Starting from the design stage of the horizontal project to work on the availability of continuous lighting compatible with the exits of fixed goods. As well as the use of the total lighting network to provide regular lighting.

\section{ELEMENTS OF CLOTHING STORE DESIGN:}

With regard to clothing stores, there are a number of basic design elements, which entrust the interior designer to work to achieve the aspects of use and aesthetic, as follows:

\section{Interface shop:}

The storefront plays a big role in attracting customers' attention and conviction, in addition to identifying

The store's identity, which depends on the designer's ability, experience and knowledge of the design considerations of the shops. These considerations apply to clothing stores, so that the exhibits are placed in a manner that is under the eye of the beholder and is Good lighting.

\section{Traffic lanes:}

Traffic lanes are one of the most important elements that determine the form of shopping, divided into main corridors and sub-corridors, which separates the main corridors between the different sections of the shop, according to the categories of goods displayed while the sub-corridors fall in the same category of the product on offer, and to achieve the pleasure of shopping and to achieve good presentation must be designed corridors It provides a smooth flow of shoppers, and the general layout is simple, in addition to the importance of the end of the corridors lead to the element of attraction in the shop.

\section{Display units:}

Display units vary within clothing stores, they are no longer a means of display only, and with increasing competitiveness increased requirements and functions of the display units to meet the needs of customers of the effective display, as well as those requirements to be units of creativity simulates the quality of the brand and products, as the materials used in the design of display units Including glass, metal and wood. The display units vary in clothing stores, some of which are within the reach of customers where they can choose from some of the product. Some of them are shelving units on the corridors or on the walls at hand and there is also hanging on special cradles, in addition to the display manikin distinctive products or models proposed by the brand. 


\section{Flooring:}

Flooring is one of the main determinants of the interior space. It is necessary to choose the appropriate floors for clothing stores to suit the colors of the proposed design and be suitable durability and resistance to friction, because of the large movement within the clothing store, and these floors should be non-slippery and easy to maintain and clean.

\section{Ceilings:}

The importance of ceilings is not only aesthetic, as they are important in the distribution of lighting and selection of the types of lighting in proportion to the proposed design, where roofs are usually designed to distribute light units. Lighting should be chosen in such a way as to provide the appropriate light for the display, and not produce heat that affects the quality and color of the clothing displayed.

\section{Mirrors:}

Mirrors are one of the most important elements in the design of clothing stores. It is the first test point for customer choice, so mirrors must be at points that allow movement in front of them, and do not interfere with traffic lanes in such a way that the customer can assess alternatives. For example, some shops modify the mirrors to make the customer appear thinner and longer so that the clothes are nicer to compensate for the narrow spaces available in front of the mirrors, and some stores add special lighting when the mirrors make the customer brighter.

\section{Changing rooms:}

One of the biggest problems of the stores is that the waiting time to enter the changing room, and the experience of the selected products will affect the customer's readiness to stay longer inside the shop. There are some treatments that are done in this regard. However, it leads to the customer feeling that they are large, and some shops increase the number of rooms with narrow spaces. changing rooms are important elements in clothing stores, because of their impact on the experience of customers and their satisfaction with the quality of service and products.

\section{Waiting areas}

To achieve the pleasure of shopping and indulge in the shopping experience for customers, must be waiting areas in clothing stores, especially in shops that have limited changing rooms, as the waiting period to enter the measurement room, experience products in the absence of places of sight, generate a sense of both boredom and fatigue, and constitute a good shopping experience For the store. So, there must be a waiting area inside the stores reflecting the brand's interest in customer satisfaction and satisfaction with the service.

\section{Accounting:}

It is one of the most important problems of shops, where customers crowded, especially in the shopping seasons, which causes problems between customers with each other or between customers and employees who work on the accounting counter, especially when the small number of accounting staff or narrow place that causes the accumulation of customers.

\section{INTERACTIVE INTERIOR DESIGN:}

The interactive design aims to shift from the traditional thinking of the space to think of it as an event, that is the addition of time factor as a fourth dimension, which increases the challenges faced during the design process for interactive products that suit the needs of users, by changing the method and methodologies used in design, By devising new methods and methodologies that address the color, texture, shape, size, space, final shape of the space and their implications for user behavior, the designer has also sought to create a scenario of interaction, interactivity and usage problems in many aspects between the user, the product and the system .

Understanding the interaction process and its dimensions in the interior design by setting the hypothesis of reaching a space in which the electronic and physical dimensions of the space are integrated without marginalizing each other. Two parts (physical equipment and electronic software), where physical equipment includes wires and equipment and communication units through which information is transmitted, Electronic programs are a set of laws and programs through which the transfer and receipt of orders. The structure of the interactive space consists of the physical and electronic structure of the space with all its contents, taking into account the possibility of an impact on each other. The interactive design can be divided into three stages or major parts.

Starting designing information, by understanding and knowing the needs, and objectives of users with different categories, defining internal space objectives and organizing content in a chart or curve to illustrate the functions of different groups, through a hierarchy of commands, so that the user can sense and interact with the space .

Moving to the interaction design phase and using interactive technology to make the internal space able to follow the activities and trends of the user with advanced and modern technology, with the aim of conceptualizing the scenario of the activities of users within the vacuum and the way they use the space, thus the process of converting information to the interaction design means converting information to the user experience .

Whereas the use of scenario, including activities that may vary depending on the category of the user and 
his previous experience is the main element affecting the rest of the elements, as the user experience affects how it is absorbed and deal with the various visual and sensory effects of the design and the resulting impact on his experience, and therefore his judgment on the quality Service at the facility. Consequently, this experience has been transformed into a benchmark for judging similar services in other facilities. Figure (2) illustrates the main elements of interactive design

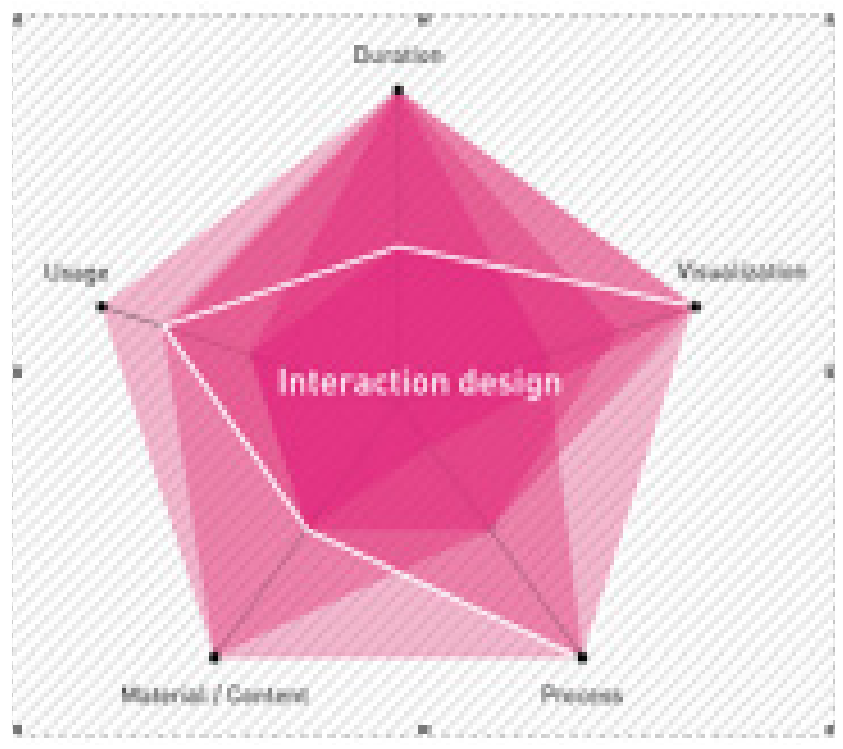

Figure (2) illustrates the basic elements of interactive design

To end the stage of design sensations according to (Jayan Narayanan, Design Strategist, User Experience (UX) and Brand Innovation Specialist) depends on the creation or creation of multiple means of input and output compatible with human senses, in order to find a new interactive experience by understanding the sensations, observing and knowing the objectives of the user, in addition to reflecting on how to design the sensations of the various functions of the internal spaces and how they relate to each other And how they are designed.

\section{OBJECTIVES OF INTERACTIVE DESIGN:}

Interactive design aims to improve human life and entertainment, through the use of digital technology and modern technologies, interactive design also aims to reduce the negative aspects (such as frustration, discomfort) to the user experience, by moving away from the complex design and provide innovative design and easy to learn, practice and use, as it enhances aspects Positive (enjoy, indulge) by providing a fun and entertaining, design that the user can enjoy in addition to being safe in use. Recognizing and understanding the interactive design process requires the continuous involvement of the user who uses the system in the design process This makes the designer able to design products and environments that maximize the use, as the involvement of users enables the designer to understand the objectives required to better interact with the system .

From the above, it can be concluded that interactive design aims to:

- Define the behavior of environments, systems and products, by defining their shape and anticipating the impact of use on human relationships and exploring the dialogue between products, people and contexts (physical, cultural, and historical).

- Provide realistic, purposeful and ethical environments, products and systems.

- Emphasize entertainment, fun and enjoyment as aspects of improvement of the user experience.

- Easy to learn and use.

- Safety (safety in use).

\section{BASICS OF INTERACTIVE DESIGN:}

The interactive design process requires the designer to be familiar with the basics of interactive design and take it as a design process. The principles of interactive design include:

Visibility, feedback, error prevention constraints, consistency, configuration or capability. Good interactive design features include: Designed to be reliable, intelligent, convenient, responsive, and enjoyable. This study showed elements of interactive design that include: space, movement, texture, appearance, time and sound.

\section{THE FOUNDATIONS OF INTERACTIVE DE- SIGN:}

The interactive design process had to be designed with full knowledge of the basics of interactive design and taken as during the stages of the design process. As the interactive design principles include: blurred vision, feedback, constraints prevent the error, consistency, configuration or possibility. The good interactive design characteristics include: to be worthy of design trustworthy, intelligent, convenient, fast response, fun. This study showed that it interactive design elements include: space or vacuum, movement, texture, appearance, time, sound. Figure (3) illustrates these characteristics, principles and elements of interactive design as follows: 


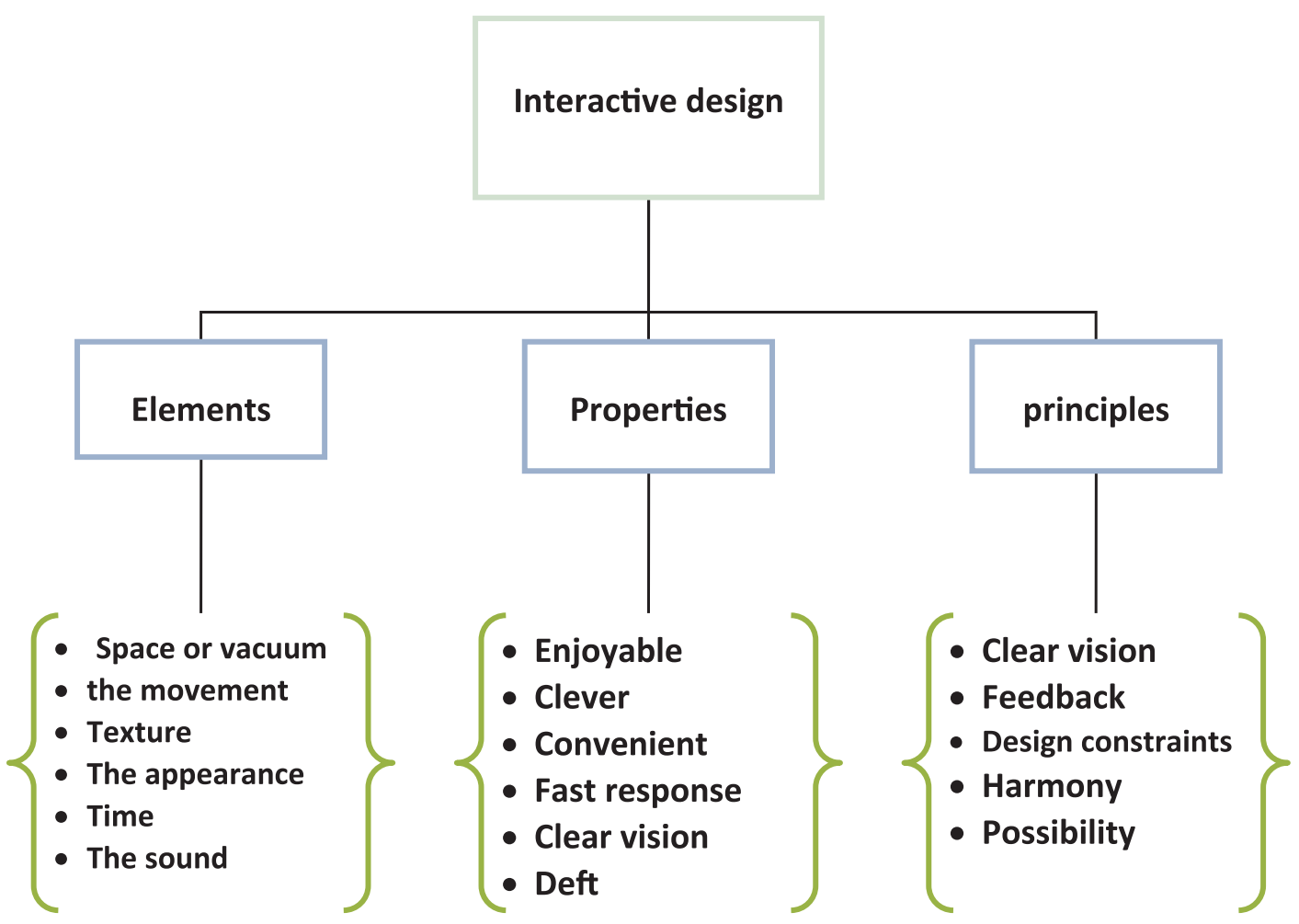

Figure (3) shows the principles and characteristics and elements of interactive design

SOME ELEMENTS OF INTERIOR DESIGN INFLUENCED BY INTERACTIVE DESIGN AND ITS APPLICATIONS:

To further explore the interactive design, and understand the nature of the interactive spaces, some elements of interior design that have been influenced by interactive design and its applications in the field of interior design will be reviewed, as it has a significant role in activating the role of interactive interior design as follows:

\section{Flooring:}

The continuous development in technology has witnessed a great development in the internal floors and reversing their impact, as the floors are no longer just a static surface, but turned into an active surface that can feel the user and maintain his safety and interact with him, where many of the interactive floors appeared modern Direct interaction with the user through consultancy equipment that interacts with the user by pressing them. At the 2008 World Expo in Spain, the floor is designed to be interactive. The amount of pressure on them, the reaction occurs through light flashes on the surface of the floor through sensors that sense the movement of the foot on them .

Interactive flooring can also be used in clothing stores as a guiding and advertising medium within the store, such as guiding customers to the changing rooms or to the exits or to the category of clothing suitable for them or where there are offers. As the interactive floor combines the perception of the movement of the body and the impact of this movement on the surfaces and the floor, these floors, turns the blanks or spaces unnoticed into a pleasant experience as a result of changing the shape of the floor depending on the movement of the person passing over it. The movement of customers inside the shop can also be tracked by changing the color of the tiles depending on the response systems, Figure (4). 


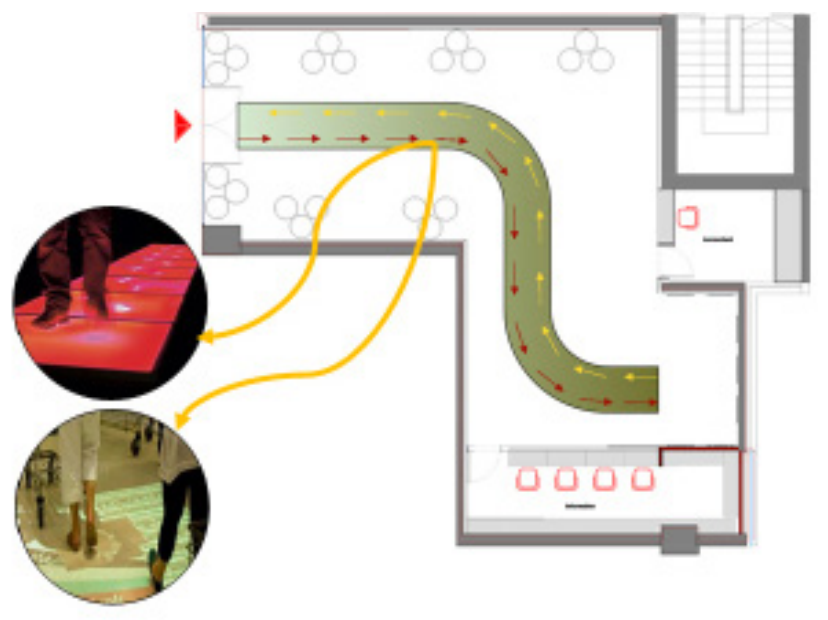

Figure (4) shows the horizontal hometown of one of the international Clothing stores Interactive flooring proposal (QUIZ)

\section{Ceiling:}

Modern technology has also contributed to the development of the roof design, whether in terms of functionality or form, contributed to make the ceilings interaction with the internal or external environment of the building, where ceilings manufactured from digital displays are used instead of traditional ceilings, so that These screens give the impression of the third dimension of the design and are used to attract attention . Whereas this technology (interactive design) can be used in the design of clothing store ceilings through the ceiling made of digital screens as a means of advertising to attract the attention of customers inside the shop and as a means of interaction with the ceiling while walking inside the shop and as a guide to the whereabouts of certain pieces or to reach the changing rooms) Figure (5). Sensors can be integrated to measure environmental conditions (humidity, or temperature) and control the amount and intensity, which is important for clothing stores where the temperature and humidity have an impact on clothing, in addition to light sensors that monitor the light patterns to reflect the visual needs of customers Inside the shop, a shopping center in Berlin also designed ceilings made of digital screens that are affected and changed colors and designed according to the weather outside the place in an interactive system.

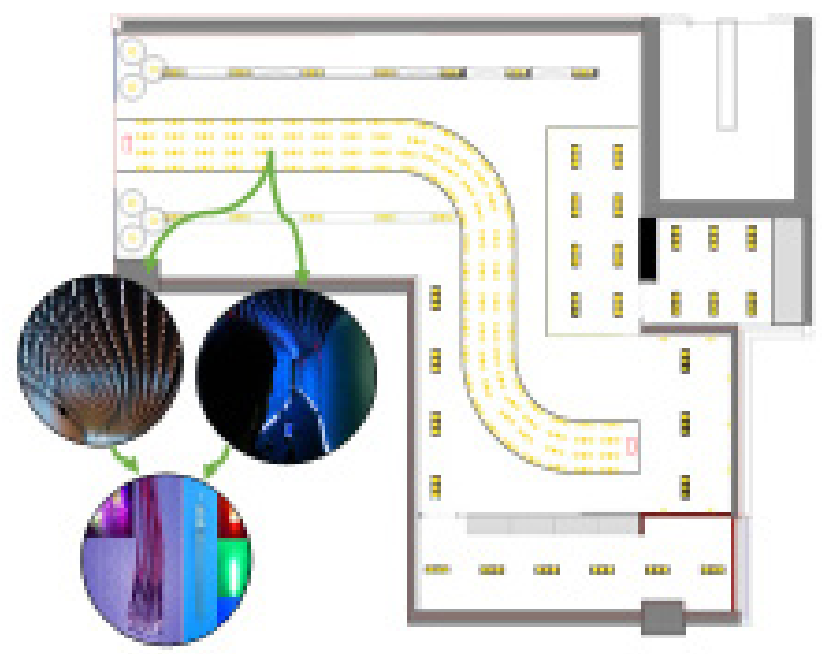

Figure (5) shows a horizontal projection of the ceiling scheme of one of The international clothing stores (QUIZ), and the proposed use of interactive ceilings

\section{Walls:}

The purpose of the interactive wall design is to interact and communicate directly with the user, as it gives the user the feeling of interaction and proximity as if in the same place, interactive walls are used, for example, in meeting rooms and conferences that take place remotely, so as to distinguish the users intimacy and interaction as If they are in the same place, they interact with each other through a system of information display units that work to interact between users and cameras and microphones installed everywhere so that communication and interaction through audio and video.

Interactive walls represent a special case of large screens equipped with special sensors and power adapters to identify and interact with the user and respond with programmed reactions. Some interact functionally or educationally .

These walls can be used to form the interior space of clothing stores through walls made of several slices fixed on one heck as a way to add elements of response and interaction within the spaces of the shop during the shopping process where these walls are flexible with the movement of visitors back and forth through motion sensors, sound and light, Which works to move the wall partitions and change the lighting, which in turn produces an interactive shopping experience within the shop, where these walls can be used in clothing stores interactive screens to be a means of the process of selecting clothes and the process of inspection and purchase directly without the need for a room to change clothes or the need to stand in a queue Payment As these walls are tasked to identify the user 
and interact with him and respond with reactions programmed to them, Figure (6).

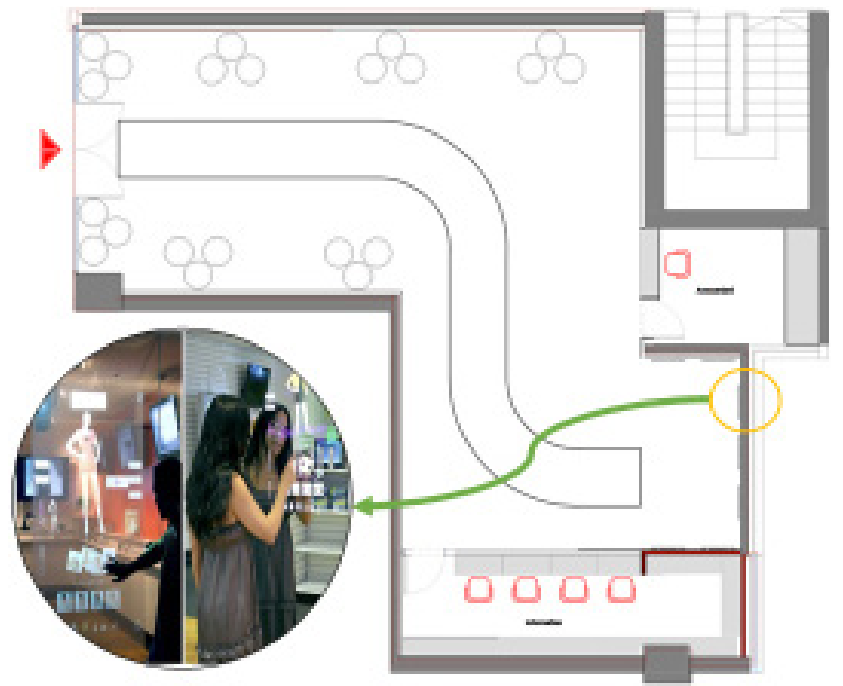

Figure (6) shows a horizontal projection of the layout of an international Clothing store (QUIZ) And the proposal to employ interactive screens in the shopping process

\section{RESEARCH RESULTS:}

1. The use of interactive techniques as a guide and advertising inside the shops of clothing has facilitated the process of selecting clothes, inspection and purchase without the need for spaces to change clothes.

2. The use of interactive technologies led to the organization of the sale and display of customers and the lack of congestion in the places of assembly.

3. Interactive design can change the perception of the surfaces that make up the interior space of clothing stores and interact with it and its continuity.

4. The use of interactive design in the determinants of the interior space of the clothing store to solve the problems prevailing in clothing stores, where interactive techniques can be used as a guide and advertising inside the shop, and as a means to attract the attention of customers inside the shop and interact with the ceiling while walking inside the clothing store, also can be exploited These techniques as a means of selecting clothes and conducting the process of inspection and purchase directly without the need for a changing room for clothes or the need to stand in line of payment.

5. The interactive design minimizes the negative aspects of the design and offers an innovative and purposeful design, easy to learn, practice and use.

6 . Interactive design enhances the positive aspects of the design by providing a fun and entertaining, design that the user can enjoy by employing different senses and improving the user experience.

\section{DISCUSSION AND CONCLUSION:}

Based on the above, it can be concluded that the use of interactive design techniques in the spaces of clothing stores will contribute positively to improve the user experience towards the service provided, increasing the chances of the user's desire to repeat the experience and visit the shop again to enjoy the services provided to him dealing with his senses effectively.

In order to achieve the pragmatic goals of clothing stores to increase the number of customers and thus increase profits, by providing a distinctive business climate, which in itself represents an additional attraction for a larger segment of target customers. On the other hand, there are greater opportunities for clothing stores to achieve additional profits, whether direct or indirect, through the possibilities of employing the different design elements available in the space of the shop.

\section{References:}

1. D. Michelle Addington, Daniel L. Schodek: Smart Materials and New Technologies. Harvard University. Elsevier. London.2005.

2. Doaa Abdul Rahman Mohammed: The Impact of Using the Digital Revolution and Smart Materials on the Design of an Interactive Inner Space". The Second International Conference of the Faculty of Applied Arts. Design between innovation and sustainability. Faculty of Applied Arts. Helwan University. Cairo (2012).

3. Halo Mohsen Mahmoudi: The role of modern energy in reducing the negative effects of interactive interior design technology. Master Thesis, Faculty of Applied Arts. Helwan University (2015).

4. Ismail Ahmed Awad, and Doaa Abdel Rahman Mohammed, and Esraa Hosni Barakat: The Effect of Using Interactive Interior Design on a Multipurpose Hall in the Cultural Center, The Fourth International Conference of the Faculty of Applied Arts, Helwan University, Cairo (2016).

5. Ola Mohamed Samir: The Impact of Using Smart Fabric on the Development of Interactive Interior Design, College Conference - Applied Arts. Helwan University. Cairo (2008).

6. Rehab Taha Youssef Abdel Fattah Hilal: Design for fun as a goal for interactive design. PhD Thesis. Faculty of Applied Arts. Helwan University. (2018).

7. Thomas Grechenig: INTERACTIVE CEILING -Ambient Information Display for Architectural Environments. Vienna University of Technology. 2008.

8. Tingting et al.: Commercial Buildings Interior Interaction Design Based on Virtual Reality Technology, Seoul World Architects Congress, UIA, 2017.

9. Wael Raafat: Interactive as a model for internal and electronic Space integration. The publication of the conference of Fine Arts in Egypt researched a hundred years of creativity. Faculty of Fine Arts. Helwan University. Cairo 2008. 